\title{
Paradigmas da Gestão do Fogo em Áreas Protegidas no Mundo e o Caso da Estação Ecológica Serra Geral do Tocantins
}

\author{
Ana Carolina Sena Barradas ${ }^{1}$, Marco Assis Borges ${ }^{1}$, Máximo Menezes Costa $^{1} \&$ Katia Torres Ribeiro $^{2}$
}

Recebido em 08/11/2019 - Aceito em 26/05/2020

1 Estação Ecológica Serra Geral do Tocantins/ICMBio, Brasil. <carolina.barradas@icmbio.gov.br, marco.borges@icmbio.gov.br, maximo.menezes@icmbio.gov.br>.

2 Instituto Chico Mendes de Conservação da Biodiversidade/ICMBio, Centro Nacional de Avaliação da Biodiversidade e Pesquisa e Conservação do Cerrado/CBC, Brasil. < katia.ribeiro@icmbio.gov.br>.

\begin{abstract}
RESUMO - Duas abordagens contrastantes de gestão do fogo podem ser observadas em áreas protegidas pelo mundo: uma está associada ao paradigma do fogo zero, pautada em políticas de proibição do uso do fogo e de exclusão do fogo nos ecossistemas e especialmente nas áreas protegidas; e outra baseada no manejo integrado do fogo, que considera o papel ecológico do fogo nos ecossistemas, suas necessidades de uso para práticas tradicionais e o contexto territorial no qual estão inseridas. Como meio termo, existe a tolerância ao fogo como um mal necessário, a ser planejado para minimizar perdas. As duas abordagens são lastreadas em questões culturais e vinculadas a diferentes conjuntos de percepções e conhecimentos científicos, culturais, sociais, ecológicos e contextos políticos, constituindo assim diferentes paradigmas na gestão ambiental e, especificamente, na gestão de unidades de conservação. O presente ensaio caracteriza e discute os dois paradigmas e os contextos em que prevalecem, traz uma reflexão sobre a dinâmica do tema no mundo, especialmente nas regiões que abrigam ecossistemas propensos ao fogo e que evoluíram com sua presença, em diálogo com a questão no Brasil, ilustrada com a experiência vivida na Estação Ecológica Serra Geral do Tocantins. Essa unidade de conservação liderou o ranking das mais incendiadas no país por muitos anos, até a implementação do manejo integrado do fogo. Concluímos com a constatação de que contextos democráticos de gestão, em esfera nacional e no âmbito das unidades de conservação, são fortemente relacionados com a adoção de práticas de uso do fogo, inclusive para a conservação da biodiversidade, recepcionando múltiplos objetivos.
\end{abstract}

Palavras-chave: Manejo adaptativo; gestão participativa; gestão territorial; comunidade tradicional; teoria ecológica.

\section{Paradigms of Fire Management in Protected Areas in the World and the Case of the Serra Geral do Tocantins Ecological Station}

ABSTRACT - Two contrasting approaches to fire management can be observed in protected areas around the world: one is associated with the zero fire perspective, based on policies to prohibit the use and to exclude fire from ecosystems, especially in protected areas; the other is based on integrated fire management, which considers the ecological role of fire in ecosystems, the importance and requirements of traditional practices and the cultural and territorial context in which they are inserted. It is also observed the tolerance to fire as a necessary evil, to be planned to minimize losses, what seems more related to the zero fire perspective. Both approaches are based on cultural issues and linked to different sets of perceptions and scientific, cultural, social, ecological and political contexts, thus constituting different paradigms in environmental management and specifically in the management of protected areas. This essay characterizes and discusses the two paradigms and the contexts in which they prevail, brings a reflection on the issue in the world, especially in regions with fire prone ecosystems, opening a dialogue with the Brazilian context, illustrated with the experience in fire management at the Serra Geral do Tocantins Ecological Station. This large protected area in Brazilian savanna led the ranking of the most burned in the country for many 
years until the implementation of integrated fire management. We conclude reinforcing the idea that democratic management contexts, at the national level and within the scope of protected areas, are strongly related to the adoption of fire use practices, including those directed to the conservation of biodiversity, thus articulating multiple objectives.

Keywords: Adaptive management; participative management; territorial management; traditional people; ecological theory.

\title{
Paradigmas de Manejo de Incendios en Áreas Protegidas en el Mundo y el Caso de la Estación Ecológica Serra Geral do Tocantins
}

\begin{abstract}
RESUMEN - Se pueden observar dos enfoques contrastantes para el manejo de incendios en áreas protegidas en todo el mundo: uno está asociado con la perspectiva de abolir los incendios, incluyendo la prohibición del uso y la exclusión del fuego de los ecosistemas, especialmente en áreas protegidas; el otro se basa en el manejo integral del fuego, que considera su papel ecológico en los ecosistemas, su importancia para las prácticas tradicionales y el contexto cultural y territorial en el que se insertan. También se observa en la gestión ambiental la tolerancia al fuego como un mal necesario, que se planificará para minimizar las pérdidas, lo que parece más relacionado, filosóficamente, con la perspectiva de abolir el fuego. Ambos enfoques se basan en cuestiones culturales y están vinculados a diferentes conjuntos de percepciones y contextos científicos, culturales, sociales, ecológicos y políticos, lo que constituye diferentes paradigmas en la gestión ambiental y específicamente en la gestión de áreas protegidas. Este ensayo caracteriza y discute los dos paradigmas y los contextos en los que prevalecen, trae una reflexión sobre el tema en Brasil, en diálogo con la dinámica del tema en el mundo, especialmente en regiones con ecosistemas propensos al fuego, y tejiendo con la experiencia vivida en la Estación Ecológica Serra Geral do Tocantins. Esta gran área protegida en la sabana brasileña lideró el ranking de las más quemadas del país durante muchos años hasta la implementación del manejo integral del fuego. Concluimos reforzando la idea de que los contextos de gestión democrática, a nivel nacional y dentro del alcance de las áreas protegidas, están fuertemente relacionados con la adopción de prácticas de empleo del fuego en el manejo, incluyendo su uso para los retos de conservación de la biodiversidad, articulando así múltiples objetivos.
\end{abstract}

Palabras clave: Manejo adaptativo; gestión participativa; gestión territorial; prácticas tradicionales; teoría ecológica.

\section{Introdução}

Em todo o mundo, duas abordagens contrastantes de gestão do fogo em vegetação nativa, com diversas nuances, são empregadas na gestão de áreas protegidas. Uma almeja a exclusão do fogo, com o uso de todos os recursos possíveis - aqui chamado de fogo zero. A outra abordagem reconhece o fogo como parte do contexto ambiental e socioeconômico e, em muitos locais, do contexto evolutivo dos próprios ecossistemas, e pode ser chamada genericamente de manejo do fogo (Whelan 1995), mas que entendemos estar melhor recepcionada no conceito de Manejo Integrado do Fogo (MIF), apresentado por Myers (2006), por se opor mais claramente à expectativa de exclusão do fogo. As abordagens se vinculam a diferenças profundas no entendimento do papel evolutivo, ecológico, social e econômico do próprio fogo (Laris \& Wardell 2006); diferenças intrínsecas nos ecossistemas que originaram as práticas de cada lugar (Goldammer 2016), na concepção da função das áreas protegidas e no entendimento do papel da sociedade na sua gestão (Arruda 2012), nas bases teóricas e nos paradigmas científicos de cada época (Wu \& Loucks 1995), dentre outros fatores.

Pela extensão de temas com que se relacionam, podemos considerar que a estratégia de fogo zero e a de manejo integrado do fogo constituem diferentes paradigmas na gestão das áreas protegidas, com rebatimentos teóricos, sociais, e na própria conservação da biodiversidade. Permeiam embates muitas vezes confusos, porque as bases das divergências nem sempre estão no nível da consciência. O assunto é extenso e complexo, e neste ensaio trazemos o debate mundial para o contexto brasileiro e concatenamos especialmente com a experiência de mudança de paradigma de gestão do fogo vivida na Estação Ecológica Serra Geral do Tocantins. 


\section{Breve apresentação da Estação Ecológica Serra Geral do Tocantins}

Criada sobre territórios tradicionalmente ocupados por comunidades quilombolas e localizada na região do Jalapão, porção setentrional do Cerrado brasileiro, a Estação Ecológica Serra Geral do Tocantins é uma extensa unidade de conservação (UC) federal, emblemática e prioritária na gestão do fogo no país. Trata-se de uma área protegida com histórico de ocorrência de megaincêndios ao longo das décadas de 2000 e 2010, e abriga, há pelo menos dez anos, discussões sobre paradigmas e abordagens de gestão do fogo de forma bem documentada.

A Estação Ecológica Serra Geral do Tocantins é a primeira UC federal a elaborar e implementar um Plano de Manejo Integrado do Fogo no Brasil, em 2014 (Barradas et al. 2014). Para além do pioneirismo em MIF, a Estação Ecológica vem protagonizando e inspirando mudanças na abordagem de gestão do fogo em áreas protegidas de Cerrado, do fogo zero para o manejo adaptativo com uso do fogo (Sax \& Angelo 2020). O processo de reabilitação do uso do fogo na UC envolve a adoção de regime de queimas prescritas em mosaico e a pactuação de termos de compromisso com a comunidade quilombola voltados à desmarginalização do uso do fogo para práticas tradicionais (Borges \& Barradas 2019).

Esse amplo contexto, aliado a um histórico de gestão do fogo bem documentado, além do empenho da equipe gestora em participar dos mais diversos fóruns de discussão sobre o tema $e$ de um grande volume de pesquisas relacionadas a fogo em andamento, justificam a adoção da Estação Ecológica Serra Geral do Tocantins como referência para nosso estudo de caso, costurando as ideias e os fatos expostos a seguir.

\section{Equilíbrio da natureza, áreas protegidas e exclusão do fogo}

A ideia de que a dinâmica da natureza tende a um equilíbrio, de que as flutuações convergem a um estado máximo de desenvolvimento que constituiria um clímax, mais estável, desejável, diverso, e que corresponderia à condição natural dos ecossistemas, permeia o desenvolvimento científico há séculos, e é explícito na ciência ecológica desde o século XIX (Wu \& Loucks 1995).
Essa ideia dialoga com a expectativa mecanicista de que seria possível modelar as respostas de todos os fenômenos, incluindo as dinâmicas populacionais e dos ecossistemas, e manejar a natureza com alto grau de previsibilidade, estando tal poder dependente apenas do conhecimento das equações e de elevada capacidade computacional (Morin 2006).

Embora já no começo do século XX alguns cientistas questionassem o alcance do conceito de balanço da natureza e de clímax dos ecossistemas, tem-se que, especialmente até as décadas de 60/70, mas ainda recentemente, essa ideia dominou tanto o desenvolvimento teórico como os desdobramentos práticos da ciência ecológica (Wu \& Loucks 1995). Na ecologia vegetal, por exemplo, existia o entendimento bastante aceito de que as comunidades vegetais mais maduras seriam homogêneas e estariam em equilíbrio ( $\mathrm{Wu}$ \& Loucks 1995), embora já houvesse evidências contrárias e contestações, como no artigo seminal de Gleason (1926), que argumentava sobre a imprevisibilidade na composição de comunidades em função das perturbações naturais e interações entre espécies.

A teoria ecológica pautada na estabilidade como situação final no desenvolvimento dos ecossistemas, associada a uma visão cristã de paraíso perdido, tem relação com a concepção das primeiras áreas protegidas do mundo contemporâneo, como territórios intocados $e$ intocáveis (Diegues 1996). Soma-se à finalidade de criação dessas primeiras áreas protegidas, chamadas genericamente de parques, a expectativa de proteger a natureza de um inevitável avanço da civilização, especialmente nos Estados Unidos e colônias ou ex-colônias europeias. Arruda (2012) traz ainda a relação da criação de áreas protegidas nacionais com a centralização do controle sobre os recursos naturais, via proteção ou outorga controlada de uso, mais intensa e explícita nas colônias (Laris \& Wardell 1996, Moura et al. 2019).

No manejo cotidiano das unidades de conservação, atualmente, um observador atento pode perceber a influência de três narrativas principais que caracterizam o ambientalismo do final do século XIX até o presente, em diferentes proporções e matizes, ao longo do tempo e região, organizadas por Arruda (2012) da seguinte forma: i. o desejo de retorno a condições mais simples de vida, em uma postura 
de regresso à terra; ii. a conservação científica, visando ao uso mais eficiente dos recursos naturais; e iii. a ideia de defesa do ambiente silvestre, a ser protegido da ação humana em crescente expansão e alcance. Entendemos que a essas três narrativas se somam, especialmente a partir dos anos 1990, o reconhecimento dos direitos dos povos e populações tradicionais, $e$ suas relações com a terra $e$ a contribuição das áreas protegidas para além de suas fronteiras em função dos serviços ecossistêmicos, incluindo os culturais (ex. Borrini-Feyerabend et al. 2004).

Em relação à proteção contra o avanço da civilização, nos EUA houve a concepção do conceito de wilderness (Arruda 2012); na verdade, bastante complexo, porque traz componentes da narrativa de retorno a um viver simples na natureza, que é realizado na gestão dos parques como um simulacro do passado nas práticas de manejo (Cowley et al. 2012), junto à ideia de proteção do Éden. Esse viver simples na natureza seria o da natureza romântica, a ser mantido na memória, como história pregressa, de modo que as populações tradicionais foram em grande parte removidas desses territórios (Diegues 1996), inclusive por uma certeza de que sua integração ao chamado desenvolvimento seria inevitável $e$ inclusive seria desejável, como se vê pelas políticas assimilacionistas (Colchester 2004). Se a presença humana não era tolerada nessas áreas protegidas, exceto para visitação, o que dizer do fogo, elemento da natureza tão importante para a cultura humana e sua história de expansão? Países que criaram parques ou outros tipos de reservas no fim do século XIX ou começo do XX, como África do Sul e Estados Unidos, por exemplo, logo estabeleceram políticas de proibição do uso do fogo (Bond \& Archibald 2003, van Wagtendonk 2007, van Wilgen 2009), embora fosse tolerado em diferentes graus em áreas agrícolas.

Em tempos de expansão da urbanização $e$ de avanços tecnológicos, o uso do fogo era - e, em muitas situações, ainda é - considerado uma técnica primitiva, sem uma ponderação quanto à forma e ao contexto (Goldammer et al. 1997, Kull 2002, Laris 2002, Boutrais 2011), de modo que a designação de áreas a serem protegidas cresce junto a uma deslegitimação das práticas tradicionais $e$ saberes populares, e à expectativa de resolução de problemas a partir de soluções exclusivamente advindas do universo técnico-científico (Laris \& Wardell 2006, Arruda 2012). Tem-se, ao longo do século XX, uma convicção crescente de que se alcançaria a exclusão do fogo com o conhecimento técnico do comportamento do fogo e investimento em equipamento e pessoal, pelo lado do combate, e com ações de conscientização da população (educação ambiental) acompanhadas de novos pacotes tecnológicos. Os grandes incêndios, frequentes nas áreas de savana manejadas sob a expectativa de exclusão do fogo, eram atribuídos a falhas na implementação de algum desses passos.

Não podemos minimizar ou desconsiderar, neste debate, o uso efetivamente destrutivo do fogo. No Brasil, a rápida conversão da Mata Atlântica, extremamente sensível a ele, em áreas de lavoura e pasto, se deu em grande parte pelo uso massivo do fogo (Dean 1996). O mesmo ocorre, há décadas, no chamado Arco do Desmatamento, na Amazônia, nos duros processos de disputa pela terra (Fearnside 2005). Junto aos desastres, na forma de incêndios catastróficos, tais fatos contribuem para a percepção do fogo, predominante na sociedade, como algo extremamente nocivo (Myers 2006).

No entanto, as relações entre os componentes ciência, gestão de áreas protegidas, cultura, política, dentre outros, são diversas e bastante ricas em possibilidades de interpretação. Por exemplo, em 1926, foi criada na África do Sul uma das primeiras unidades de conservação do mundo, o Kruger National Park, e até 1948 os gestores do parque admitiam queimadas para renovação das pastagens nativas, em parte pela baixa implementação da unidade e pouca equipe (Bond \& Archibald 2003). O ano de 1948 é emblemático na África do Sul, por marcar o início do apartheid, regime de segregação racial implementado no país até 1994. Coincidentemente ou não, é a partir daquele ano que passa a ser aplicada a lógica da exclusão do fogo na gestão desse parque, vigente até 1956, devido a uma antipatia, à época, pelo fogo na vegetação (Bond \& Archibald 2003). A abordagem é alterada pela ocorrência de severos incêndios. Houve, então, a adoção de diferentes políticas, em geral acompanhadas ou derivadas de experimentos científicos, tais como queimas em talhões em desenhos rígidos, progressiva inserção de variações neste esquema inicial, e depois a aceitação de incêndios por raios e combate aos de origem antrópica, neste caso, na busca de um regime que seria natural. Esta estratégia também foi abandonada em 1992 após incêndios catastróficos. A partir de então, predomina o 
objetivo mais amplo, mas também mais abstrato, de "conservação da biodiversidade", com desafios próprios que serão discutidos abaixo. O contexto sul-africano é bastante distinto, comparado aos parques em outros países, por ter tido o manejo voltado - em grande parte - a grupos específicos da fauna, os grandes herbívoros - incluindo manejo da paisagem para obtenção de pastagem $e$ abate de animais para promoção e manutenção de uma esperada capacidade de suporte (Bond \& Archibald 2003), e não o manejo para proteção de uma biodiversidade prístina.

Ecólogos como Bond \& Archibald (2003) e van Wilgen (2009) interpretaram que a proibição do uso do fogo no Kruger National Park esteve associada aos diferentes objetivos de manejo - grandes herbívoros, conservação da biodiversidade ou busca de retorno a uma (desconhecida) condição original. No entanto, os gestores que dirigiram o parque em diferentes contextos políticos, e refletiram juntos sobre sua experiência (Mabunda et al. 2003), argumentaram sobre a importância do cenário sociopolítico, em grande parte do tempo segregacionista, nas tomadas de decisóes para conservação. O governo sul-africano utilizou os parques para criar uma identidade e unidade entre os brancos daquele país, componente de um programa de elevação da autoestima desta parte da população após os estragos da grande depressão e das duas grandes guerras, e com isso afastaram os negros de sentimentos de pertencimento em relação aos parques nacionais (também removendo-os das vilas que existiam dentro do parque, como Skukuza) (Mabunda et al. 2003). Práticas ancestrais de manejo das savanas foram desprezadas e não incorporadas no manejo do parque.

Há outras coincidências temporais entre políticas segregacionistas e a expectativa de exclusão do fogo, como nos Estados Unidos, onde a abordagem de gestão em unidades de conservação pautada na exclusão do fogo prevaleceu de 1886 a 1967 (van Wagtendonk 2007). Esse período coincide com a vigência de leis segregacionistas no país, como as "leis de Jim Crow", que vigoraram entre 1876 e 1965. As leis de Jim Crow (ou "código dos negros") foram leis locais e estaduais, promulgadas especialmente nos estados do sul dos Estados Unidos, que institucionalizaram a segregação racial, afetando afro-americanos, indígenas e outros grupos étnicos. Essas leis criavam instalações separadas para brancos e negros, separando-os em escolas, hotéis e restaurantes, lojas, composições ferroviárias, bondes, teatros, cinemas, parques de diversões, cemitérios e lugares de reuniões públicas.

Já na Austrália, políticas segregacionistas se relacionam com alterações drásticas no regime de fogo nas regiões de savana no início do século XX, quando a população aborígene teve um declínio catastrófico devido a doenças, translocação e massacres do período colonial (Moura et al. 2019), época em que os indígenas australianos eram incluídos entre os animais pela Lei da Fauna e Flora. Em 1993, o governo australiano permitiu que os aborígenes pleiteassem terras sob um regime de comum acordo de título (desde que não se extinguissem títulos pré-existentes de uso da terra). Mas somente no início dos anos 2000 houve incentivos reais para que os aborígenes implementassem iniciativas de manejo do fogo nas savanas, atualmente com bons resultados alcançados, incluindo redução de conflitos, valorização de práticas tradicionais, conservação da biodiversidade e incorporação de carbono no solo (Cook et al. 2012, Russel-Smith et al. 2013, Moura et al. 2019).

A complexidade dos cenários e os desafios às interpretações de como o contexto sociopolítico influencia na gestão do fogo podem ser ilustrados com o descrito por Laris \& Wardell (2006) para diversos países da África Ocidental em áreas savânicas não protegidas formalmente e com predominância de ocupação comunitária. Nesses países de independência tardia (Libéria é o primeiro a ter a independência reconhecida, em 1947), houve aplicação da política de exclusão do fogo no começo do século XX por um entendimento generalizado de que o fogo prejudicava as florestas, que, por sua vez, eram o alvo priorizado pela administração colonial. Havia um desprezo pelas formações savânicas por um entendimento de que eram uma degradação das florestas por uso excessivo do fogo, em função de técnicas primitivas. A exclusão do fogo foi sendo relaxada no final do período colonial nesses países, fosse por falta de recursos, fosse pelo fato de técnicos com experiência de campo, atuantes nas áreas mais ermas, terem outras percepções quanto aos seus efeitos e sua importância socioeconômica. A política de exclusão do fogo volta com toda a intensidade após a independência (em alguns países, como Burkina Faso, sob regimes autoritários), coincidindo com períodos de seca 
severa, e se abranda com a abertura de espaços democráticos, especialmente em escala de comunidade (Laris \& Wardell 2006, aqui exposto de forma bastante simplificada).

Pode ser então que a coincidência entre períodos de segregação racial e implementação de políticas de exclusão do fogo ou de uso do fogo em bases muito rígidas, como no caso da África do Sul, seja mediada por um outro fator, que é a gestão verticalizada, sem espaços democráticos, seja no governo dos países em questão, seja na gestão de suas áreas protegidas (consideramos aqui que há, muitas vezes, um descompasso entre essas escalas, pela inércia de assimilação institucional de novas práticas, vide Kueffer et al. 2012). Há muitas situações de gestão vertical em que a narrativa da ciência e da técnica, mal entendida e mal aplicada do ponto de vista epistemológico, se impõe como a única legítima, acessível apenas aos reconhecidos como pesquisadores e a um conjunto de técnicos de elite, e que se corromperiam ao dialogar com a realidade e com a sociedade na busca de soluções multifacetadas.

No caso da Estação Ecológica Serra Geral do Tocantins, assumimos que a UC vivenciou a lógica do paradigma do fogo zero entre 2001, ano de sua criação, e 2012, período em que a gestão priorizou ações sistemáticas de combate ao fogo, de fiscalização e de controle das práticas tradicionais de uso do fogo. Nessa época, sugerimos que a gestão da UC era desempenhada, basicamente, de forma tecnocrática, com pouca ou nenhuma participação social, o que endossa a ideia de que a verticalização da gestão pode ter implicação direta no enrijecimento da visão sobre o papel do fogo.

$\mathrm{Na}$ vigência desse paradigma na Estação Ecológica, assim como observado no tempo colonial em países da África, o uso do fogo pelas comunidades tradicionais era visto como uma atividade precária e sem técnica. As pessoas das comunidades, incluídos os quilombolas, eram vistas como incendiárias, $e$ as iniciativas de educação ambiental na área de abrangência da UC e seu entorno tinham como objetivo "educar" os usuários do fogo para que assimilassem protocolos institucionais de queimas controladas ou para que adotassem práticas alternativas que substituíssem o uso fogo. Essa postura gerencial desprezou, por mais de uma década, oportunidades reais de incorporar as comunidades locais no projeto de conservação do território da UC (Lindoso 2014).
Contudo, diferentemente das experiências de fogo zero relatadas para África do Sul e para alguns países da África Ocidental, por exemplo, a gestão do fogo na Estação Ecológica Serra Geral do Tocantins nunca foi pautada na teoria ecológica da estabilidade dos ecossistemas, provavelmente em função de sua criação recente. Desde o começo havia aceitação do papel ecológico do fogo no Cerrado. Apesar de não haver registros de expectativas de exclusão total do fogo na Estação Ecológica, os gestores se apegaram a uma noção vaga de "excesso de fogo" (não havia limiares que sugerissem quanto de fogo poderia ser considerado tolerável ou em excesso), o que os levava a repetidas e impetuosas ações de combate que, ao longo de anos, alimentaram a ocorrência de grandes incêndios e as percepções profundamente negativas quanto à passagem do fogo na UC.

\section{Rompendo paradigmas}

Nos ecossistemas propensos à passagem do fogo, as políticas de proibição total ou uso apenas na confecção de aceiros e outras medidas de controle da propagação não apresentaram bons resultados para a conservação da natureza (Myers 2006, Laris \& Werdell 2006, Goldammer 2016, Durigan \& Ratter 2016). Perda de biodiversidade é uma das consequências frequentemente apontadas por ecólogos, seja pela homogeneização ambiental decorrente da reincidência de grandes e severos incêndios favorecidos pelo acúmulo e continuidade de material combustível (van Wagtendonk 2007, van Wilgen 2009, Durigan \& Ratter 2016), seja devido à substituição de ecossistemas abertos por fisionomias florestais em situações de ausência de fogo, com perda de espécies de áreas abertas (Pinheiro \& Durigan 2009).

A frequência e a severidade de incêndios aumentaram em áreas protegidas após a adoção de políticas pautadas no paradigma do fogo zero. $\mathrm{Na}$ África do Sul, temos exemplos nos Parques Nacionais do Kruger e do Etosha (Du Plessis 1997, van Wilgen 2009), que sofreram com grandes eventos de fogo associados ao acúmulo e continuidade de combustível. Nos Estados Unidos, grandes incêndios foram registrados nos parques Yellowstone e Cerrogrande no final do século XX (van Wagtendonk 2007). No Brasil, temos o exemplo recente do Parque Nacional da Chapada dos Veadeiros, que, em 2017, teve 78\% de sua área queimada (Fidelis et al. 2018), entre 
outros grandes eventos ocorridos nos parques da Chapada Diamantina, Serra do Cipó e Canastra (Berlinck \& Ribeiro 2012).

Eventos extremos colocaram em evidência as limitações logísticas e financeiras para controlar, combater e suprimir eventos tão grandes, cada vez mais frequentes, assim como a impossibilidade dos órgãos gestores de sustentarem a busca da exclusão do fogo, incluindo países com recursos (Bond \& Archibald 2003, van Wagtendonk 2007, Laris \& Wardell 2006, Berlinck \& Ribeiro 2012, Fidelis et al. 2018).

Às avaliações críticas de resultados $e$ limitações da abordagem de gestão pautada na exclusão do fogo somaram-se, a partir das décadas de 1980/1990, as discussões na área da ecologia sobre a importância da heterogeneidade espacial, mas também da heterogeneidade temporal/ assincronia dos ecossistemas, e emergia a teoria do não-equilíbrio e dos múltiplos equilíbrios ( $\mathrm{Wu}$ \& Loucks 1995). Tem-se, então, uma compreensão de que a paisagem é composta por ecossistemas em diferentes estágios sucessionais e diferentes dinâmicas próprias, o que promove diversidade ao ampliar as possibilidades de coexistência entre espécies e janelas de oportunidades para diferentes grupos. A heterogeneidade dos ecossistemas seria mantida de forma dinâmica pelas interações entre organismos, pela variabilidade ambiental e pelas perturbações (Wu \& Loucks 1995).

Em tal contexto científico e ecológico, distúrbios naturais, mesmo que mediados pelas necessidades ou ações humanas, passaram a ser considerados importantes nos processos de modelagem da paisagem e manutenção dos processos ecossistêmicos (Hardesty et al. 2005, Bond et al. 2005) e mesmo na manutenção da biodiversidade (Martin \& Sapsis 1992, Bowman et al.2016). No caso do fogo, tem-se como premissa que, nos ecossistemas com história evolutiva associada ao fogo, quanto mais diversificados os regimes de queima (extensão, sazonalidade, frequência, intensidade - mas, atenção, em escala de paisagem), maior a biodiversidade, entendendo que a heterogeneidade é uma chave para a biodiversidade (Martin \& Sapsis 1992, Laris \& Wardell 2006).

A teoria ecológica pautada na estabilidade como situação final no desenvolvimento dos ecossistemas dispunha de pouco ferramental para lidar com a dinâmica e heterogeneidade no tempo e no espaço. Há, então, progressiva incorporação de campos da ciência da complexidade, que reúne conceitos como imprevisibilidade, incerteza, dependência de escala, padrões emergentes, dentre outros (Morin 2006). Essa nova abordagem científica se dá em diálogo com mudanças na sociedade e, como a ciência é parte da cultura, se desdobra na forma de influência recíproca. Como exemplo, na administração há o desenvolvimento dos conceitos de gestão adaptativa, em que o planejamento acontece a partir da observação periódica do planejado em relação ao ocorrido, em postura de permanente aprendizado (Senge 1990), e de abertura às expectativas de diferentes públicos, estas também dinâmicas, em parte porque são afetadas pelos próprios resultados anteriores.

A mudança de paradigma na gestão do fogo não se deu apenas pelo acúmulo conceitual. $\mathrm{O}$ quarto final do século XX é também marcado pela abertura de espaços democráticos, como em vários países da América do Sul e África, pelo fortalecimento e diversificação de movimentos sociais e pelo rompimento das políticas de segregação racial em diversos países, como Estados Unidos, África do Sul e Austrália. Nessa conjuntura, os conflitos socioambientais vieram à tona, de forma que as comunidades e os povos que usavam o fogo como ferramenta de manejo passaram a reagir à política de exclusão do fogo, reivindicando o direito de uso para sua subsistência (Mabunda et al. 2003, FAO 2003, Moura et al. 2019), assim como o respeito à sua cultura e visão de mundo. Essas mudanças de cenários e de paradigmas ecológicos e sociais parecem ter sido determinantes para o questionamento e declínio da política de exclusão do fogo em várias unidades de conservação no mundo (Bond \& Archibald 2003, van Wagtendonk 2007, van Wilgen 2009, Eloy et al. 2019).

$\mathrm{Na}$ Estação Ecológica Serra Geral do Tocantins, o processo de mudança de paradigma na gestão do fogo foi marcado por avaliações críticas e, em parte, bastante objetivas dos resultados da abordagem pautada em políticas de fogo zero. A reocorrência (anual) de megaeventos de incêndios devido ao acúmulo e continuidade do material combustível colocou em cheque a abordagem de gestão focada em combate $e$ marginalização do uso do fogo. Por mais que fossem se elevando os investimentos em sistema de controle e combate aos incêndios, os eventos extremos superavam a capacidade de resposta do órgão ambiental (Barradas 2017). 
Para além da frustração associada à recorrência de grandes incêndios, os gestores da Estação Ecológica tiveram que lidar também com o acirramento de conflitos socioambientais relacionados às expectativas de controle $e$ proibições de uso do fogo. A comunidade, insatisfeita, se organizou e exigiu reconhecimento $e$ aceitação de suas práticas tradicionais, o que se deu no final dos anos 2000 e início dos anos 2010 (Lindoso 2014), época em que a UC também se abria para a gestão participativa, com o processo de criação do seu conselho consultivo.

As comunidades quilombolas do Jalapão tiveram importante poder $e$ influência no processo de mudança na gestão do fogo na Estação Ecológica Serra Geral do Tocantins. Protagonizaram a desmarginalização do uso do fogo, especialmente nos longos debates que permitiram a assinatura de termos de compromisso entre os moradores e a gestão da unidade, um marco na superação institucional de barreiras variadas que levavam à condenação do uso do fogo. Ao passo que a comunidade ganhava maior protagonismo na gestão do fogo, os gestores diretamente envolvidos com o tema tiveram oportunidades robustas de reflexão sobre o papel social do fogo na região, sobre os profundos conhecimentos acerca do comportamento e riscos do fogo e sua relação com a paisagem $e$ manejo dos recursos, apesar das limitações de compreensão do modo de vida quilombola.

Importante propulsor de mudanças na gestão do fogo na Estação Ecológica foi, sem dúvida, o Projeto Cerrado-Jalapão, que teve como objetivo principal aprimorar a prevenção $e$ o controle do fogo na região do Jalapão. O projeto estimulou a participação social e ofereceu várias oportunidades de intercâmbio com equipes de outras áreas protegidas e de outros países, o que propiciou maior reflexão dos gestores sobre a necessidade de uso do fogo (http://cerradojalapao. mma.gov.br/biblioteca/arquivos).

\section{Do manejo do fogo ao manejo integrado do fogo}

O desenvolvimento de novos conceitos em ecologia e, especificamente na ecologia das savanas e do Cerrado, levou ao questionamento do âmago da política de exclusão do fogo - mesmo que fosse possível, não seria desejável.
A constatação da impotência do paradigma do fogo zero em ecossistemas propensos à passagem do fogo provoca a abertura das instituições e dos técnicos para outras possibilidades de gestão. O manejo com uso do fogo se apresenta como alternativa técnica e ecológica de gestão, mas que poderia ficar restrito ao controle de combustível e/ou proteção de formações vegetais mais sensíveis ou visar à sustentabilidade dos ecossistemas em coexistência com seres humanos.

Laris \& Wardell (2006) contrastam uma abordagem de manejo em que o fogo é considerado um mal necessário (necessary evil), e outra em que o fogo é uma necessidade (necessity). Gestões que têm o fogo como um mal necessário focam na necessidade de minimizar seus efeitos. Nas savanas, em geral, ela corresponde ao modelo de condenação ao fogo tardio na estação seca, $e$ de aceitação do fogo precoce (começo da estação seca), mas apenas em circunstâncias específicas $e$ controladas, $e$ muitas vezes fortemente burocratizadas. $\mathrm{Na}$ abordagem em que o fogo é uma necessidade, o fogo é tido como uma ferramenta necessária não só para evitar incêndios, mas também como uma necessidade ecológica, que interage com as necessidades sociais de utilização da paisagem savânica.

Myers (2006) organiza as ideias acima diferenciando o "manejo do fogo" do "manejo integrado do fogo". Como uma derivação do "triângulo do fogo", imagem muito conhecida de quem lida com combate a incêndios (trata das condições indispensáveis à ocorrência de fogo: combustível, oxigênio e fonte de ignição), o triângulo do manejo do fogo apresenta as ações empregadas em três conjuntos - as de prevenção, de combate e as de uso do fogo. Já o manejo integrado do fogo (MIF), também apresentado como um triângulo, tem, em um dos lados, o manejo do fogo, com a prevenção, o combate e seu uso como ferramenta; no segundo lado, a ecologia do fogo, que reúne os atributos ecológicos do fogo e sua relação com a biodiversidade; e do terceiro lado, a cultura do fogo, com as necessidades e os impactos socioeconômicos. No manejo do fogo, o uso visa preponderantemente evitar danos maiores - aceiros negros, controle pontual do combustível, podendo se dar junto a práticas agrícolas nas chamadas queimas controladas. Já no MIF, as decisões de manejo deveriam recepcionar diferentes perspectivas e expectativas, 
em espaços de diálogo e de planejamento participativo e inclusivo, de modo a ser viável acordar coletivamente os objetivos de manejo, ampliando também a colaboração para que sejam alcançados. O MIF tem relação com a qualidade da governança das áreas.

Mesmo onde há relativo consenso teórico e bom ambiente de gestão, a reabilitação do uso do fogo para manejo no dia a dia das áreas protegidas não é trivial. Como registram Bond \& Archibald (2003), no caso do Parque Nacional do Kruger, na África do Sul, embora houvesse nos anos 1990 um consenso quanto à necessidade de mudar a política de gestão do fogo, usando-o de forma mais ativa para a conservação da biodiversidade, a sua implementação foi e ainda é extremamente complexa e difícil.

Entendemos que boa parte dessa dificuldade se deve ao fato de que o objetivo "conservar a biodiversidade", embora nobre e pertinente, é muito amplo e abstrato, o que faz com que sejam imensamente mais difícil de planejar e chegar a um acordo sobre o que fazer em termos de manejo em comparação com um objetivo relativamente simples, em termos de objetivo final, que é a exclusão do fogo. Isso ocorre porque a definição de uma política de uso do fogo com fins ecológicos (ainda sem considerar os pleitos sociais) requer a verbalização de resultados esperados a serem alcançados, $e$ diferentes pesquisadores e gestores costumam apresentar diferentes prioridades conforme os componentes da biodiversidade que conhecem melhor (ver, para exemplo, Figueira et al. 2016) ou que dão maior valor (ex. florestas versus campos, mamíferos versus insetos, diversidade funcional ou diversidade filogenética - Brilhante \& Fiedler 2011). Observa-se, muitas vezes, uma paralisia, um impasse, até mesmo entre pesquisadores defensores do uso extensivo do fogo, em função do infindável conjunto de "lacunas de conhecimento" sobre a dinâmica própria de cada grupo ou espécie perante os regimes de fogo. Nesse contexto, é comum não se avançar muito além de propostas de queimas no entorno de ambientes sensíveis, como matas de galeria e capões de mata, para protegê-los.

Como forma de vencer essa paralisia, um sistema atualmente bastante aceito de manejo do fogo em savanas busca a implementação de diversos regimes, em mosaico espaço-temporal de áreas queimadas - a chamada queima em mosaico.
É como se a área estivesse sendo colorida com os resultados de queimas aplicadas em diferentes tempos, estações e intensidades - conforme práticas tradicionais ou nelas inspiradas (Moura et al. 2019, Sax \& Angelo 2020), como exposto a seguir. Essa abordagem se relaciona com a hipótese de Martin \& Sapsis (1992) de que a pirodiversidade promove biodiversidade, elaborada a partir de estudos sobre o efeito das mudanças de regimes de fogo ao longo do século XX sobre a biodiversidade.

Alguns pesquisadores criticam o sistema de manejo em mosaico pela imprecisão dos níveis de pirodiversidade necessários para a biodiversidade e pela falta de pesquisas específicas e diretrizes operacionais para sua implementação (Parr \& Andersen 2006, Driscoll et al. 2010).

Entendemos que a queima em mosaico não representa, necessariamente, o regime mais desejável. Entretanto, a prática é preferível, diante da ameaça em curso de homogeneização da paisagem decorrente das políticas de fogo zero e as necessidades ecológicas e culturais da paisagem. Considerando que as incertezas são inerentes a qualquer processo de intervenção e manejo em áreas protegidas, os gestores que defendem a adoção do regime de mosaico em áreas savânicas ou campestres propensas ao fogo argumentam ser uma abordagem adequada para iniciar o manejo do fogo em escala de paisagem, que pode - e deve - ser aprimorado com maior aporte de conhecimentos e objetivos de manejo.

Uma longa iniciação em uso do fogo foi necessária para que, em 2014, a equipe gestora da Estação Ecológica Serra Geral do Tocantins elaborasse o primeiro Plano de Manejo Integrado do Fogo do Brasil (Barradas et al. 2014), que previu o início de queimas prescritas na UC. O primeiro Plano de MIF da Estação Ecológica Serra Geral do Tocantins foi elaborado em junho de 2014, logo após uma missão técnica-institucional à Austrália que teve como objetivo apresentar componentes de MIF que estão sendo aplicados no norte do país. Foram visitados territórios indígenas, parques nacionais, universidades, órgãos executivos de elaboração e implementação de políticas públicas e colegiados envolvidos na gestão do fogo no país. Apesar do plano ter forte influência de experiências australianas de queima em mosaico, o objetivo do manejo inicial de MIF na Estação Ecológica foi moldado por expectativas majoritariamente conservacionistas, visando à fragmentação da paisagem, homogeneizada pela ocorrência de 
extensos incêndios, e também alteração da sazonalidade do fogo na UC (aumento da área queimada precocemente - no início da estação seca - em substituição ao fogo de alta intensidade, comum no final da estação seca). Essa expectativa de manejo pode ser relacionada à interpretação do uso do fogo como um mal necessário, sugerida por Laris \& Wardell (2006).

A exemplo do Parque Nacional do Kruger (primeira unidade de conservação do mundo a usar o fogo para proteção da biodiversidade), o uso do fogo na Estação Ecológica vem se ajustando às estratégias de acordo com as experiências $e$ evolução dos objetivos de gestão. A partir de 2017, a UC passou a admitir queimas tardias não só como uma necessidade do ecossistema, mas, principalmente, das comunidades. A essa época, os gestores amadureceram sua compreensão em relação à pirodiversidade (Barradas 2017) e, mais recentemente, passaram a reconhecer e a valorizar a tecnologia tradicional local de queima em mosaico (Sax \& Angelo 2020).

Em geral, em várias áreas protegidas do mundo, observa-se também uma profícua relação entre projetos de pesquisa e o avanço no manejo, especialmente com a demanda por subsídio científico para a gestão do fogo na escala de paisagem, e a exigência de incorporação $e$ interpretação do manejo tradicional. Tais desafios têm levado a comunidade científica a aceitar e a propor experimentos que não seguem a expectativa de controle amplo das variáveis, no que Funtowicz \& Ravetz (1995) chamam desenvolvimento de uma ciência pós-normal (que se aventura para além das chamadas CNTPs - condições normais de temperatura e pressão), ou que Kueffer et al. 2012 discutem no campo das pesquisas voltadas a grandes questões da sociedade.

\section{Desmarginalização do uso do fogo, direitos sociais e conhecimento tradicional}

Do ponto de vista da relação entre ciência e gestão, é interessante refletir sobre o expresso por Laris \& Wardell (2006): "muitos modelos ecológicos contemporâneos para as savanas e estratégias de manejo do fogo permanecem profundamente influenciadas pelas ideias de cientistas coloniais. Em parte, isso ocorre porque as abordagens de manejo do fogo continuam avaliando os impactos do fogo da perspectiva de parcelas isoladas mais do que da paisagem mais ampla. Por essa perspectiva estreita, os impactos negativos do fogo parecem superar os positivos. Quando vistos da perspectiva mais ampla da ecologia de paisagem, no entanto, os impactos mais benéficos do manejo indígena ganham destaque" (tradução livre).

Como visto acima, a biodiversidade $e$ sua relação com o fogo já representam um conjunto muito grande de desafios na gestão com vistas ao manejo de áreas protegidas. Mas os conflitos sociais $e$ as injustiças ambientais contra comunidades tradicionais advindos da proibição do uso do fogo (Little 2001) são cada vez mais reconhecidos. Tem-se, então, um outro vetor de transformação no manejo com uso do fogo, que resulta da luta pelo reconhecimento de direitos das comunidades tradicionais - direitos territoriais, $e$ direito à expressão e ao reconhecimento de sua cultura e conhecimentos, sem deixar de reconhecer os severos limites à sinergia entre a lógica institucional de gestão do fogo $e$ as formas de vida das comunidades (Fagundes 2019a, 2019b). Essa história recente é bem narrada por autores como Cook et al. (2012) e Moura et al. (2019).

As práticas tradicionais, em geral, alcançam um rol amplo de objetivos, desde o manejo de pastagens ao controle de pragas e de incêndios catastróficos, e são adequadas a cada região $e$ a diferentes realidades sociais, muitas vezes em sistemas de decisão e governança voltados ao manejo do fogo (Melo \& Saito 2011, Falleiro et al. 2016). A queima em mosaico é uma prática tradicional realizada por muitos desses povos que usam o fogo na paisagem favorecendo a heterogeneidade ambiental, e traz a possibilidade de estabelecimento de arranjos espaciais e temporais de modo a alcançar múltiplos objetivos de conservação e a gestão de conflitos socioambientais.

A Austrália é o país que se destaca em cenário mundial pela incorporação do uso do fogo por populações tradicionais no manejo das unidades de conservação e áreas protegidas, tanto pela sistematização do conhecimento tradicional como na participação direta de aborígenes na concepção e implementação das ações de manejo. Nesse contexto de gestão integrada, foi criado o Bushfires Council of the Northern Territory, um conselho que conta com a participação de diferentes atores sociais que atuam 
no Território Norte da Austrália, incluindo grupos indígenas, comunidades tradicionais, membros da comunidade científica e representantes do governo (Morrison \& Cooke 2003, Russell-Smith et al. 2013). Para o manejo, associou-se o uso de tecnologias, como imagens de satélite de alta resolução e o mapeamento de cicatrizes de queimadas, às técnicas de decisão e de queima utilizadas por grupos indígenas e moradores locais (Russell-Smith et al. 2013).

Também na Austrália destaca-se o projeto WALFA (West Arnhem Land Fire Abatement), uma estratégia de manejo integrado do fogo implementada desde 2005 entre o governo australiano e aborígenes, e que visa ao reestabelecimento dos regimes de fogo de quando as terras eram manejadas pelos aborígenes (Fitzsimons et al. 2012). Um dos resultados mais enfatizados no projeto, dada sua importância no contexto global, é a redução de emissões de gases de efeitos estufa decorrente da mudança da sazonalidade do fogo, ou seja, mudanças na época do ano de maior ocorrência de fogo (Russel-Smith et al. 2013, Fitzsimons et al. 2012).

Na África do Sul, o manejo do fogo com base comunitária nos parques nacionais não é uma abordagem disseminada. Após o fim do apartheid não houve políticas que incentivassem o retorno dos povos e comunidades tradicionais para o interior das unidades de conservação. Não obstante, observa-se na África do Sul uma preocupação em envolver mais efetivamente as comunidades vizinhas na gestão dos parques; por exemplo, em 1995 foi criado no Kruger um departamento de Ecologia Social (Mabunda et al. 2003). A despeito disso, Mabunda et al. (2003) consideram que ainda existe um longo caminho a ser percorrido no país para despertar e promover nas comunidades que vivem nos entornos dos parques nacionais um sentimento de pertencimento. $\mathrm{O}$ discurso de que a conservação dos parques sul-africanos deve ser garantida por meio do apoio da maioria da população negra do país também foi defendido por Nelson Mandela, em 1998, quando da comemoração do centenário do parque.

Trazendo um caso da América do Sul, Bilbao et al. 2010 relatam o manejo integrado do fogo no Parque Nacional Canaima, na Venezuela, sobreposto ao território tradicionalmente ocupado pelo povo Pemón, que usa o fogo para atividades diversas. O parque abrange ecossistemas florestais (sensiveis ao fogo), savânicos (propensos ao fogo) e zonas de transição floresta-savana, localmente chamadas de turetakata, cujos ecossistemas podem ser considerados influenciados pelo fogo. Índios Pemón que compunham a brigada do parque realizaram queimadas nas zonas de transição floresta-savana, testando diferentes frequências de queima, e os resultados mostraram a importância do manejo praticado pelos Pemón, que leva à formação de mosaicos para a proteção da vegetação sensível ao fogo.

Observa-se em várias áreas protegidas, como na Estação Ecológica Serra Geral do Tocantins, que foi a chegada dos pleitos $e$ proposições das comunidades residentes, muitas vezes em condições conflituosas e polêmicas, que levou ao início do manejo do fogo, inclusive para fins ecológicos. De certa forma, existe uma resistência cultural e um conjunto de receios tão grande entre os gestores para iniciar o manejo com uso do fogo, que é a concretude das necessidades e exigências das pessoas residentes na unidade que aceleram a tomada de decisão. E saber o porquê $e$ o como as pessoas queimam é essencial para alinhar os desencontros entre as políticas de uso do fogo, as visões de mundo dos que elaboram as regras e as realidades locais (Mistry \& Bizerril 2011). Nesse contexto, o processo para elaboração dos termos de compromisso e a assinatura em si dos acordos propiciaram maior aproximação $e$ construção de relações de confiança entre os gestores da UC e a comunidade quilombola, ampliando entendimentos sobre o papel do fogo no Jalapão e viabilizando o acordo sobre práticas de manejo, inclusive mais ousadas.

Mas nem sempre houve receptividade com relação aos pontos de vista da comunidade sobre as necessidades ecológicas e sociais de uso do fogo. O primeiro termo de compromisso, assinado em 2012, quando a Estação Ecológica ainda estava rompendo o paradigma de fogo zero, apresentou normas inéditas de permissão de uso do fogo em UC de proteção integral, sendo considerado um marco na abertura institucional para gestão participativa na UC. Ainda assim, o instrumento apresentou fortes traços de um sistema de comando-e-controle do órgão gestor, refletindo, ao final, muito mais o poder do Instituto Chico Mendes de Conservação da Biodiversidade (ICMBio) do que os reais anseios e necessidades da comunidade (Lindoso 2014). 
No entanto, a implementação e o monitoramento do termo de compromisso coincidindo com as primeiras queimas prescritas da UC - serviram como um convite à reflexão $e$ respeito aos temas levantados pelos quilombolas. Assim, as regras mais arbitrárias foram expostas a críticas, tornando nítida a necessidade de revisão do termo de compromisso, de modo que houvesse maior compatibilidade com o modo de vida da comunidade local.

Para que mudanças reais ocorressem, foi fundamental a fixação de servidores do ICMBio na UC, que sustentaram - e ainda sustentam - essas relações a longo prazo. Em 2018, um novo termo de compromisso foi assinado; desta vez, com uma integração mais equilibrada de expectativas e necessidades de conservação e dos modos de vida geraizeiros, com reconhecimento $e$ valorização das técnicas ancestrais de queimas em mosaico. Passados dois anos de implementação do novo acordo, até o momento nenhuma cláusula foi contestada ou descumprida pelas partes, $e$ a relação gestores-quilombolas, outrora muito conflituosa, agora é mutuamente considerada como uma oportunidade de parceria e troca de aprendizados, que seguem amadurecendo.

\section{Reflexões sobre este debate no Brasil}

O modelo de gestão pautado no manejo integrado do fogo ainda é novidade no Brasil, e sua institucionalização em áreas protegidas, incipiente. Ainda são muito recentes no país as experiências que vêm rompendo o paradigma de fogo zero (Falleiro et al. 2016, Schmidt et al. 2018, Fidelis et al. 2018).

Apesar de alguns avanços, o tema fogo segue causando polêmicas e controvérsias nos atos da administração pública brasileira - o que é compreensível, considerando as diversidades econômica, social e de ecossistemas associadas à enorme extensão do país e a diversidade de percepções em relação ao tema, baseadas em vivências distintas.

Por um lado, é inegável que a gestão pública ambiental vem ampliando entendimentos sobre o papel ecológico e social do fogo, especialmente nos ecossistemas savânicos, sendo observada a institucionalização do manejo integrado do fogo em órgãos como o Instituto Brasileiro do Meio Ambiente e dos Recursos Naturais Renováveis (Ibama) e no ICMBio. Por outro lado, eventos catastróficos de incêndio no Brasil contribuem para a percepção do fogo como algo extremamente nocivo pela população de forma geral. As queimadas na Amazônia, por exemplo, em 2019, causaram grande repercussão e comoção pública, reforçando socialmente as normas e os procedimentos que limitam o fogo a algo que precisa ser combatido ou relacionado apenas a práticas destrutivas.

É necessário considerar que, antes da construção de Brasília, inaugurada em 1960, a elaboração das normativas e dos entendimentos sobre o país se deu preponderantemente ao longo do litoral, na Mata Atlântica, onde se concentravam as principais instituições $e$ universidades públicas. Muito embora se reconheça que a Floresta Amazônica e a Mata Atlântica têm necessidades de uso do fogo muito diferentes das do Cerrado, por exemplo, entendemos que a experiência florestal tenha se destacado na institucionalização de políticas de exclusão do fogo em todo o território nacional, desconsiderando as particularidades dos demais biomas. Overbeck et al. (2015) trazem ampla apreciação da necessidade de políticas diferenciadas para ecossistemas não florestais, não apenas quanto ao fogo, mas até mesmo quanto ao vocabulário - por exemplo, o desafio de se encontrarem substitutos para expressões como incêndio florestal, reposição florestal, desmatamento, dentre outros.

Embora a legislação federal apresente tom predominantemente proibitivo quanto ao uso do fogo na vegetação (Brasil 1934, Brasil 1965, Brasil 1979, Brasil 1998, Brasil 2012), observamos que todas normativas também apresentam ressalvas que possibilitam seu uso, seja para fins ecológicos, produtivos ou de proteção. A implementação dessas exceções, no entanto, encontra barreiras burocráticas, como a exigência de comprovação de domínio territorial, e também a aceitação, por parte do corpo técnico das instituições, fundamental para que os meios sejam buscados e viabilizados, incluindo a desburocratização (Mistry \& Bizerril 2011, Berlinck \& Ribeiro 2012, Durigan \& Ratter 2016, Eloy et al. 2019).

Berlinck \& Ribeiro (2012) entendem que, para superar as barreiras para institucionalização do manejo integrado do fogo no âmbito das áreas protegidas, é necessário o fortalecimento 
e a capacitação de corpo técnico especializado, o fomento à pesquisa e a sistematização de informações, e a definição de uma estratégia $e$ política institucional para se avançar concretamente, com respaldo técnico-científico e político. Atrelado a essas recomendações, é essencial que o manejo integrado do fogo no Brasil internalize os princípios e diretrizes do manejo adaptativo, como pactuação de objetivos, aceitação do risco e ambiente de permanente aprendizado.

No contexto brasileiro, a experiência da Estação Ecológica Serra Geral do Tocantins vem inspirando a adoção do MIF em um conjunto expressivo de áreas protegidas, além de subsidiar discussões sobre princípios e diretrizes para o manejo integrado do fogo em unidades de conservação federais. Entre 2013 e 2019, a Estação Ecológica foi palco de, pelo menos, três grandes eventos institucionais de intercâmbio em MIF, dos quais participaram gestores de outras UCs federais, entre outros convidados (Barradas et al. 2020). Os gestores da Estação Ecológica também participam de grupos de trabalho, instituídos no âmbito do ICMBio, direcionados à normatização do MIF em UCs, contribuindo diretamente na elaboração de orientações institucionais voltadas à elaboração de planos específicos e trilhas de aprendizagem em MIF.

\section{Considerações Finais}

O manejo integrado do fogo emerge como tendência de gestão em áreas protegidas, especialmente naquelas de biomas savânicos, $e$ resulta da constatação da necessidade de adotar novas abordagens de gestão que considerem, de forma articulada, o papel ecológico do fogo nos ecossistemas $e$ as necessidades de uso do fogo pelas comunidades locais, sobretudo aquelas detentoras de práticas tradicionais e o contexto territorial no qual estão inseridas.

Reiteramos, neste processo, a importância da implementação do Sistema Nacional de Unidades de Conservação (SNUC) na abertura democrática da gestão das unidades de conservação. São elementos de destaque a obrigatoriedade dos conselhos gestores nas unidades de conservação, assim como o estabelecimento de termos de compromisso com os povos e comunidades tradicionais, como já mencionado, o que se dá por meio de processos de negociação de necessidades, expectativas e balizas legais (Talbot 2016). Tem-se, ainda, a participação do Ministério Público, visando ao respeito à Convenção no 169 da Organização Internacional do Trabalho (OIT), conhecida como OIT 169, sobre povos indígenas e tribais, que passou a vigorar no Brasil em julho de 2003, além da intensa capacitação dos servidores do ICMBio para a implementação da gestão participativa (Mendonça \& Talbot 2014).

Para lidar com a multiplicidade políticosocial relacionada ao fogo no Brasil, é importante reconhecer a diversidade de efeitos do fogo sobre os ecossistemas, as distintas consequências sociais e econômicas (Myers 2006), lidando com múltiplas necessidades de uso (Mistry \& Bezerril 2011), e as complexas respostas desses sistemas socioecológicos. É fundamental manter os fóruns de compartilhamento de expectativas e aprendizados sobre o manejo do fogo, em diversas escalas, assim como a possibilidade de tratar, de forma aberta, um tema controverso, para que os princípios do manejo adaptativo na gestão sejam alcançados e se avance na integração entre expectativas, conhecimentos e percepções, de maneira dialogada na sociedade.

\section{Agradecimentos}

À Escola Nacional de Botânica Tropical do Jardim Botânico do Rio de Janeiro, pela oportunidade de reflexões durante o curso do Mestrado Profissional em Biodiversidade em Unidades de Conservação que impulsionaram a redação deste artigo à primeira autora. Ao Instituto Chico Mendes de Conservação da Biodiversidade, pelo incentivo, pela oportunidade de capacitação e de aprendizados pela prática. A todos gestores, brigadistas, funcionários e parceiros que colaboraram e ajudaram a imprimir a história da gestão do fogo na Estação Ecológica Serra Geral do Tocantins. Aos revisores anônimos que contribuíram bastante com a clareza do texto.

\section{Referências Bibliográficas}

Arruda RSV. 2012. Desenvolvimento local e povos tradicionais em áreas protegidas. p. 85-99. In: Lima GS et al. (org.) Gestão, pesquisa e conservação em áreas protegidas. Universidade Federal de Viçosa. 230p.

Barradas ACS, Borges MA \& Máximo M. 2014. Plano de Manejo Integrado do Fogo 2014. ESEC Serra Geral 
do Tocantins. Instituto Chico Mendes de Conservação da Biodiversidade (ICMBio). Rio da Conceição. 15p.

Barradas ACS. 2017. A gestão do fogo na Estação Ecológica Serra Geral do Tocantins, Brasil. Dissertação (Mestrado Profissional em Biodiversidade em Unidades de Conservação). Escola Nacional de Botânica Tropical, Jardim Botânico do Rio de Janeiro. 123p.

Barradas ACS \& Borges MA. 2019. Termos de Compromisso: um instrumento de pactuação ou de controle do uso e manejo dos recursos naturais em unidades de conservação de proteção integral? In: Anais do IX Seminário Brasileiro sobre Áreas Protegidas e Inclusão Social.

Barradas ACS, Borges MA \& Costa MM. 2020 Plano de Manejo Integrado do Fogo da Estação Ecológica do Tocantins 2020. ICMBio. 12p.

Berlinck CN \& Ribeiro KT. 2012. Pesquisa e manejo do fogo em áreas protegidas federais. p. 119-135. In: Lima GS et al. (orgs.). Gestão, pesquisa e conservação em áreas protegidas. Universidade Federal de Viçosa. 230p.

Bilbao BA, Leal AV \& Méndez CL. Indigenous use of fire and forest loss in Canaima National Park, Venezuela. Assessment of and tools for alternative strategies of fire management in Pemón indigenous lands. Human Ecology, 38(5): 663-673, 2010.

Brasil. 1934. Decreto Federal $n^{\circ} 23.793$, de 23 de janeiro de 1934. <http://legislacao.planalto.gov.br/ legisla/legislacao.nsf/Viw_Identificacao/dec\%2023.7931934? OpenDocument>. Acesso em: 15/03/2020.

Brasil. 1965. Lei Federal $n^{\circ} 4.771$, de 15 de setembro de 1965. <http://www.planalto.gov.br/ccivil_03/leis/ 14771.htm >. Acesso em: 15/032020.

Brasil. 1979. Decreto Federal $n^{\circ} 84.017$, de 21 de setembro de 1979. <http://www.planalto.gov.br/ ccivil_03/Atos/decretos/1979/D84017.html.>. Acesso em: $15 / 03 / 2020$.

Brasil. 1998. Decreto Federal no 2.661, de 08 de julho de 1988. < http://www.planalto.gov.br/ccivil_03/decreto/ D2661.htm. >. Acesso em: 15/03/2020.

Brasil. 2012. Lei Federal $n^{\circ}$ 12.651/2012. <http:// www.planalto.gov.br/ccivil_03/_ato2011-2014/2012/ lei/112651.htm. . . Acesso em: 15/03/2020.

Bond WJ \& Archibald S. Confronting complexity: fire policy choices in South African savanna parks. International Journal of Wildland Fire, 12(4): 381-389, 2003.

Bond WJ, Woodward FI \& Midgley GF. The global distribution of ecosystems in a world without fire. New Phytologist, 165 (2): 525-538, 2005.
Borges MA \& Barradas ACS. 2019. Queima em mosaico: como o conhecimento tradicional está contribuindo para redução de incêndios no Jalapão, Brasil. In: Anais do IX Seminário Brasileiro sobre Áreas Protegidas e Inclusão Social, Recife.

Borrini-Feyerabend G, Kothari A \& Oviedo G. 2004. Indigenous and local communities and protected areas: towards equity and enhanced conservation. IUCN, Gland, Switzerland and Cambridge, UK. xviii + 111p.

Boutrais J. 2011. Pastoralism and protected areas in West and East Africa. p. 143-166. In: Aubertin C \& Rodary E (eds.). Protected areas. Sustainable land? Ashgate. 219p.

Bowman DM et al. Pyrodiversity is the coupling of biodiversity and fire regimes in food webs. Philosophical Transactions of the Royal Society of London B, 371(1696): 20150169, 2016.

Colchester M. Conservation policy and indigenous peoples. Environmental science \& policy, 7(3): 145-153, 2004.

Cook GD, Jackson S \& Williams RJ. 2012. A revolution in northern Australian fire management: recognition of Indigenous knowledge, practice and management. Pp. 293-305. In: Flammable australia. Collingwood: CSIRO Publishing. 462p.

Cowley J, Landres P, Memory M, Scott D \& Lindholm A. 2012. Integrating cultural resources and wilderness character. ParkScience, 28 (3). <http://www.nature.nps. gov/ParkScience/index.cfm?ArticleID $=537 \&$ Page $=1>$.

Dean W. 1996. A Ferro e fogo: a história e a devastação da Mata Atlântica brasileira. Companhia das Letras. 484p.

Diegues ACS. 1996. O mito moderno da natureza intocada. Ed Hucitec. 176p.

Driscoll DA, Lindenmayer DB, Bennett AF, Bode M, Bradstock RA, Cary GJ \& Gill M. Fire management for biodiversity conservation: key research questions and our capacity to answer them. Biological Conservation, 143(9): 1928-1939, 2010.

Du Plessis WP. Refinements to the burning strategy in the Etosha National Park, Namibia. Koedoe, 40 (1): 63-76, 1997.

Durigan G \& Ratter JA. The need for a consistent fire policy for Cerrado conservation. Journal of Applied Ecology, 53 (1): 11-15, 2016.

Eloy L, Mistry J, Bilbao B, Schmidt IB. From fire suppression to fire management: advances and resistances to changes in fire policy in the savannas of Brazil and Venezuela. The Geographical Journal, 1: 1-13, 2019. 
Fagundes GM. 2019a. Fogos Gerais: Transformações Tecnopolíticas na Conservação do Cerrado (Jalapão, TO). Tese (Doutorado em Antropologia). Universidade de Brasília. 444p.

Fagundes GM. Normatividades do fogo: conservação ambiental e formas de vida quilombola na savana brasileira. Vibrant: Virtual Brazilian Anthropology, 16, $2019 b$.

Falleiro RM, Santana MT \& Berni CR. As contribuições do Manejo Integrado do Fogo para o controle dos incêndios florestais nas Terras Indígenas do Brasil. Biodiversidade Brasileira, 6(2): 88-105, 2016.

Fearnside PM. Deforestation in Brazilian Amazonia: history, rates, and consequences. Conservation Biology, 19(3), 680-688, 2005.

Fidelis A \& Pivello VR. Deve-se usar o fogo como instrumento de manejo no Cerrado e Campos Sulinos? Biodiversidade Brasileira, 1(2): 12-25, 2011.

Fidelis A, Alvarado ST, Barradas ACS \& Pivello VR. The year 2017: megafires and management in the Cerrado. Fire, 1(3): 49, 2018.

Figueira JEC et al. 2016. Fire in Rupestrian Grasslands: Plant Response and Management. Fernandes GW (ed.). In: Ecology and conservation of mountaintop grasslands in Brazil. DOI: 10.1007/978-3-319-29808-5_18. Springer.

Fitzsimons $\mathrm{J}$ et al. Insights into the biodiversity and social benchmarking components of the Northern Australian fire management and carbon abatement programmes. Ecological Management \& Restoration, 13(1), 51-57, 2012.

Funtowicz SO \& Ravetz JR. The worth of a songbird: Ecological economics as a post-normal science. Ecological Economics, 10(3): 197-207, 1994.

Gleason HA. The individualistic concept of the plant association. Bulletin of the Torrey Botanical Club, 53: 1-20, 1926.

Goldammer J. Use of prescribed fire in land management, nature conservation and forestry in temperate-boreal Eurasia. Biodiversidade Brasileira, 6(2): 6-26, 2016.

Hardesty J, Myers R \& Fulks W. Fire, ecosystems, and people: a preliminary assessment of fire as a global conservation issue. The George Wright Forum, 22: 78-87, 2005.

Kueffer $\mathrm{C}$ et al. Enabling effective problem-oriented research for sustainable development. Ecology and Society, 17(4): 8, 2012. DOI: http://dx.doi.org/10.5751.

Kull CA. Madagascar aflame: landscape burning as peasant protest, resistance, or a resource management tool? Political Geography, 21: 927-953, 2002.
Laris P. Burning the seasonal mosaic: preventative burning strategies in the wooded savanna of Southern Mali. Human Ecology, 30: 155-186, 2002.

Laris P \& Wardell DA. Good, bad or 'necessary evil'? Reinterpreting the colonial burning experiments in the savanna landscapes of West Africa. The Geographical Journal, 172(4): 271-290, 2006.

Lindoso LDC. 2014. Recursos de uso comum nos gerais do Jalapão: uma análise institucionalista do termo de compromisso com populações tradicionais no interior de unidades de conservação. Dissertação (Mestrado em Desenvolvimento Territorial). Universidade Federal do Tocantins. 207p.

Little PE. 2001. Os conflitos socioambientais: um campo de estudo e de ação política, p. 107-122. In: Burrsztyn M (ed.) A difícil sustentabilidade: política energética e conflitos ambientais. Garamond. 257p.

Mabunda D, Pienaar DJ \& Verhoef J. 2003. The Kruger National Park: a century of management and research, p. 3-21. In: du Toit JT, Rogers KH \& Biggs HC (eds.). The Kruger experience: ecology and management of savanna heterogeneity. Island Press.

Martin RE \& Sapsis DB. 1992. Fires as agents of biodiversity: pyrodiversity promotes biodiversity. In: Proceedings of the Conference on Biodiversity of Northwest California Ecosystems. Cooperative Extension, University of California, Berkeley.

Medeiros MB \& Fiedler NC. Heterogeneidade de ecossistemas, modelos de desequilíbrio e distúrbios. Biodiversidade Brasileira, 1(2): 4-11, 2011.

Melo MM \& Saito CH. Regime de queima das caçadas com uso do fogo realizadas pelos Xavante no Cerrado. Biodiversidade Brasileira, 1(2): 97-109, 2011.

Mendonça F \& Talbot V. Participação social na gestão de unidades de conservação: uma leitura sobre a contribuição do Instituto Chico Mendes. Biodiversidade Brasileira, 4(1): 211-234, 2014.

Mistry J \& Bizerril M. Por que é importante entender as inter-relações entre pessoas, fogo e áreas protegidas? Biodiversidade Brasileira, 1(2): 40-49, 2011.

Morrison JH \& Cooke PM. 2003. Caring for country: Indigenous people managing country using fire with particular emphasis on Northern Australia, p. 1-10. In: Proceedings of National Landcare Conference. Darwin, Australia. <https://gfmc.online/wp-content/uploads/3IWFC-014-Morrison.pdf>

Moura LC, Scariot AO, Schmidt IB, Beatty R \& RussellSmith J. The legacy of colonial fire management policies on traditional livelihoods and ecological sustainability in savannas: Impacts, consequences, new directions. Journal of Environmental Management, 232: 600-606, 2019. 
Myers RL. 2006. Convivendo com o fogo. Manutenção dos ecossistemas e subsistência com o manejo integrado do fogo. The Nature Conservancy, Tallahassee. 36p.

Morin E. 2006. Introdução ao pensamento complexo. Editora Sulina. 120p.

Overbeck GE et al. Conservation In Brazil Needs To Include Non-forestEcosystems. Diversity and Distribution, 21: 1455-1460, 2015. DOI: 10.1111/ddi.12380.

Parr CL \& Andersen AN. Patch mosaic burning for biodiversity conservation: a critique of the pyrodiversity paradigm. Conservation Biology, 20: 1610-1619, 2006.

Pinheiro EDS \& Durigan G. Dinâmica espaço-temporal (1962-2006) das fitofisionomias em unidade de conservação do Cerrado no sudeste do Brasil. Brazilian Journal of Botany, 32(3): 441-454, 2009.

Russell-Smith J, Cook GD, Cooke PM, Edwards AC, Lendrum M, Meyer CP \& Whitehead PJ. Managing fire regimes in north Australian savannas: applying Aboriginal approaches to contemporary global problems. Frontiers in Ecology and the Environment 11, e55-e63, 2013.

Sax S \& Angelo M. 2020. Painting with fire: Cerrado land managers learn from traditional peoples. Mongabay. $<$ https://news.mongabay.com/2020/03/painting-withfire-cerrado-land-managers-learn-from-traditionalpeoples/\# > . Acesso em: 15/04/2020.

Schmidt IB, Moura LC, Ferreira MC, Eloy L, Sampaio $\mathrm{AB}$, Dias PA \& Berlinck $\mathrm{CN}$. Fire management in the Brazilian Savanna: first steps and the way forward. Journal of Applied Ecology, 55: 2094-2101, 2018.
Senge PM. 1990. The Fifth Discipline: The Art and Practice of the Learning Organization. Currency Doubleday. 356p.

Van Wagtendonk JW. The history and evolution of wildland fire use. Fire Ecology, 3(2), 3-17, 2007.

Van Wilgen BW. The evolution of fire management practices in savanna protected areas in South Africa. South African Journal of Science, 105 (9-10): 343-349, 2009.

Van Wilgen BW, Govender N \& Biggs HC. The contribution of fire research to fire management: a critical review of a long-term experiment in the Kruger National Park, South Africa. Int. J. Wildl. Fire, 16: 519-530, 2007.

Van Wilgen BW, Govender, N \& MacFadyen S. An assessment of the implementation and outcomes of recent changes to fire management in the Kruger National Park. Koedoe, 50: 22-321, 2008.

Whelan RJ. 1995. The Ecology of Fire. Cambridge University Press, Cambridge, UK. 350p.

$\mathrm{Wu} \mathrm{J}$ \& Loucks OL. From balance of nature to hierarchical patch dynamics: a paradigm shift in ecology. The Quarterly Review of biology, 70(4), 439-466, 1995.

Talbot V. 2016. Termos de Compromisso: Histórico e Perspectivas como Estratégia para a Gestão de Conflitos em Unidades de Conservação Federais. Dissertação (Mestrado em Biodiversidade em Unidades de Conservação). Escola Nacional de Botânica Tropical/ JBRJ. Rio de Janeiro. 219p.

\section{Biodiversidade Brasileira - BioBrasil.}

Edição temática: Diálogos entre a Academia e a Gestão de Áreas Protegidas:

Programa de Pós-Graduação Profissional - Biodiversidade em Unidades de Conservação

n. 2,2020

http://www.icmbio.gov.br/revistaeletronica/index.php/BioBR

Biodiversidade Brasileira é uma publicação eletrônica científica do Instituto Chico Mendes de

Conservação da Biodiversidade (ICMBio) que tem como objetivo fomentar a discussão e a disseminação de experiências em conservação e manejo, com foco em unidades de conservação $e$ espécies ameaçadas. 